Technical Paper

Special articles: JCREN III

特集 : JCREN III

\title{
Catalytic Esterification of Palm Fatty Acid Distillate into Biodiesel Over Sulfonated Iron Oxide Catalyst
}

\author{
Michelle MATIUS $* 1 * 2$ and Mohd Sufri MASTULI $* 1 * 2 \dagger$
}

(Received January 5, 2021)

\begin{abstract}
The palm fatty acid distillate (PFAD), as a low-cost feedstock, was catalytically esterified into biodiesel (also known as fatty acid methyl ester, FAME) using sulfonated iron oxide $\left(\mathrm{HSO}_{3}{ }^{-} / \mathrm{Fe}_{2} \mathrm{O}_{3}\right)$ catalyst. In this work, the catalyst was synthesised via self-propagating combustion (SPC) method, towards a greener synthesis technique, followed by sulfonation with chlorosulfonic acid $\left(\mathrm{HSO}_{3} \mathrm{Cl}\right)$ to enhance the catalyst's acid properties. The catalysts were characterised and the success of sulfonation process was determined. From this study, $\mathrm{Fe}_{2} \mathrm{O}_{3}$ catalysts were proven to be pure and single-phase. The success of the sulfonation then was verified by the presence of sulfur, functional groups of $\mathrm{S}-\mathrm{O}$ asymmetric vibration and $\mathrm{S}=\mathrm{O}$ symmetric vibration, and increasing total acidity. Then, the sulfonated $\mathrm{Fe}_{2} \mathrm{O}_{3}$ catalyst was used to esterify the PFAD feedstock in methanol in which the esterification parameters were also optimized to obtain maximum free fatty acid (FFA) conversion. It was found that 15:1 of methanol-to-PFAD molar ratio, $4 \mathrm{wt} . \%$ of catalyst loading, $80^{\circ} \mathrm{C}$ of reaction temperature and $5 \mathrm{~h}$ of reaction time produced $95.5 \%$ of FFA conversion. Interestingly, the sulfonated $\mathrm{Fe}_{2} \mathrm{O}_{3}$ catalyst can be considered as a superacid solid catalyst that enables boosting the esterification of the PFAD feedstock into biodiesel.
\end{abstract}

\section{Key Words}

Esterification, Biodiesel, PFAD, Catalyst, $\mathrm{Fe}_{2} \mathrm{O}_{3}$

\section{Introduction}

Biodiesel can be an alternative fuel for diesel engines due to its several advantages over petrol-diesel fuel. Biodiesel is readily available, biodegradable, non-toxic, and

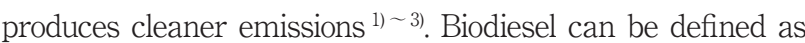
a mixture of the mono-alkyl ester of long-chain fatty acid, which can be produced through the esterification of free fatty acids (FFA) and transesterification of triglycerides (TG). The first-generation biodiesel which was derived from high-value edible feedstock, such as soybean, sunflower oil and rapeseed oil, are highly popular in the first-world countries where there are no food-versus-food issue. With tropical climates of Malaysia, palm is one of the most popular and extensively cultivated plants which contributes to almost $80 \%$ of world production ${ }^{4}$. Therefore, the use

※1 Centre for Functional Materials and Nanotechnology, Institute of Science, Universiti Teknologi MARA 40450 Shah Alam, Selangor, Malaysia

※2 School of Chemistry and Environment, Faculty of Applied Sciences, Universiti Teknologi MARA 40450 Shah Alam, Selangor, Malaysia

$\uparrow$ Corresponding author: mohdsufri@uitm.edu.my of low-cost and non-edible feedstock such as palm fatty acid distillate (PFAD) can reduce the cost and increase its sustainability. The PFAD is a by-product from crude palm oil (CPO) refining process, which contains $>80 \%$ of FFA ${ }^{5)}$ 6). In Malaysia, PFAD is cheap and highly abundant, which makes the PFAD as a potential sustainable source of feedstock for the esterification process to produce biodiesel with the presence of alcohol and catalyst ${ }^{6)} \sim 8$. Heterogeneous solid acid catalyst is preferable to be used for high FFA content feedstock because it is easy to separate, less corrosive and reusable. Thus, the production cost can be reduced due to less wastewater treatment and less production steps ${ }^{9}$. Solid acid catalyst such as iron oxide $\left(\mathrm{Fe}_{2} \mathrm{O}_{3}\right)$ was used as dopant for sulfated tin(IV) oxide ${ }^{10)}$ and aluminium oxide ${ }^{11}$, and gained much attention due to their ability to esterify and transesterify high FFA feedstock simultaneously ${ }^{12)}$. However, the utilization of mixed metal increases the total cost. Instead of using as a dopant, single metal oxide catalyst of $\mathrm{Fe}_{2} \mathrm{O}_{3}$ has more merit and the study regarding this catalyst is still very limited. Since the PFAD feedstock contained higher FFA, a superacid catalyst 
is desired. Therefore, sulfonation by chlorosulfonic acid was performed to enhance the catalytic activity of $\mathrm{Fe}_{2} \mathrm{O}_{3}$ catalyst ${ }^{13)}$. In this study, the $\mathrm{Fe}_{2} \mathrm{O}_{3}$ catalyst was synthesised using the self-propagating combustion (SPC) method and activated with chlorosulfonic acid. The catalyst properties were systematically characterised. Various esterification parameters such as methanol-to-PFAD molar ratio, catalyst loading, reaction temperature and reaction time were also investigated and optimised.

\section{Methodology}

\subsection{PFAD feedstock}

The PFAD feedstock used in this study was obtained from Jomalina R\&D, Sime Darby Sdn Bhd, Klang, Selangor, Malaysia. The feedstock was characterized according to American Oil Chemists' Society (AOCS) official method such as moisture content (AOCS Ca 2b-38), saponification value (AOCS TI 1a-64) and acid value (AOCS Cd 3d-63).

\subsection{Catalysts synthesis and characterisation}

Stoichiometric amounts of $98.0 \%$ purity iron(III) nitrate nonahydrate $\left(\mathrm{Fe}\left(\mathrm{NO}_{3}\right)_{3} .9 \mathrm{H}_{2} \mathrm{O}\right)$ and $99.5 \%$ purity citric acid $\left(\mathrm{C}_{6} \mathrm{H}_{8} \mathrm{O}_{7}\right)$ were dissolved separately in a minimum volume of deionised water. Both solutions were mixed continuously followed by heating at $350{ }^{\circ} \mathrm{C}$ until combustion occurs, resulting in a reddish-brown coloured precursor which was calcined at $600^{\circ} \mathrm{C}$ for $6 \mathrm{~h}$ to give a pure $\mathrm{Fe}_{2} \mathrm{O}_{3}$ catalyst. Subsequently, about $2 \mathrm{~g}$ of $\mathrm{Fe}_{2} \mathrm{O}_{3}$ was added into $100 \mathrm{~mL}$ of a round-bottom flask followed by addition of $2 \mathrm{~mL}$ of $99.0 \%$ purity concentrated $\mathrm{HSO}_{3} \mathrm{Cl}$ while stirring. The mixture was stirred gently for $1 \mathrm{~h}$ at room temperature. Then, the sulfonated catalyst was rinsed with methanol for multiple times, and the excess solvent was separated through centrifugation. Lastly, the sulfonated $\mathrm{Fe}_{2} \mathrm{O}_{3}$ catalysts were dried in an oven at $100{ }^{\circ} \mathrm{C}$ for overnight. All the obtained catalysts were characterised using simultaneous thermogravimetric analysis (STA), powder X-Ray diffraction (XRD), field emission scanning electron microscopy equipped with energy dispersive X-Ray spectroscopy (FESEM-EDX), attenuated total reflection-Fourier transform infrared (ATRFTIR) spectroscopy, Brunauer-Emmett-Teller (BET) and temperature-programmed desorption of ammonia (TPD-
$\left.\mathrm{NH}_{3}\right)$

\subsection{Catalytic esterification of PFAD feedstock}

The PFAD esterification was carried out using the conventional reflux system. The initial control set of parameters were methanol-to-PFAD molar ratio of 9:1, catalyst loading of $1 \mathrm{wt} . \%$, reaction temperature of $120^{\circ} \mathrm{C}$ and reaction time of $5 \mathrm{~h}$. At this initial control set, the methanol-to-PFAD molar ratio varied from 3:1 to 21:1 to determine the optimum ratio. Next, the catalyst loading was also changed between 1 wt.\% and 5 wt.\% to obtain the optimum catalyst loading. Then, the reaction temperature of $80^{\circ} \mathrm{C}$ was increased progressively to $160^{\circ} \mathrm{C}$ to determine the optimum temperature. Lastly, the reaction time was prolonged from $1 \mathrm{~h}$ until $6 \mathrm{~h}$ to obtain the optimum time. About $5 \mathrm{~g}$ of PFAD was mixed with the required amount of methanol and catalyst, and then it was refluxed at the desired temperature and time under continuous stirring. After the reaction completed, the cooled reaction mixture was centrifuged to collect the catalyst and the remaining product was left overnight for separation between methanol (upper layer) and biodiesel (bottom layer). The biodiesel samples were analysed by titration method to determine the acid value and FFA conversion.

\section{Results and discussion}

\subsection{Properties of PFAD feedstock}

Table 1 shows the physicochemical properties of PFAD feedstock, featuring other non-edible oils such as castor seed oil and waste cooking oil (WCO). It was found that PFAD has higher FFA content than the other two oils. The fatty acid composition of PFAD was determined using gas chromatography-mass spectrometry (GC-MS), and the results are tabulated in Table 2 . The major fatty acids in

Table 2 Fatty acid composition of PFAD

\begin{tabular}{ccc}
\hline Fatty acids & Molecular formula & Composition (wt.\%) \\
\hline Myristic acid & $\mathrm{C}_{14} \mathrm{H}_{28} \mathrm{O}_{2}$ & 0.9 \\
Oleic acid & $\mathrm{C}_{18} \mathrm{H}_{34} \mathrm{O}_{2}$ & 34.1 \\
Palmitic acid & $\mathrm{C}_{16} \mathrm{H}_{32} \mathrm{O}_{2}$ & 50.5 \\
Stearic acid & $\mathrm{C}_{18} \mathrm{H}_{36} \mathrm{O}_{2}$ & 3.2 \\
Linoleic acid & $\mathrm{C}_{18} \mathrm{H}_{32} \mathrm{O}_{2}$ & 6.3 \\
\hline
\end{tabular}

Table 1 Physicochemical properties of PFAD

\begin{tabular}{lccc}
\hline \multicolumn{1}{c}{ Properties } & PFAD & Castor seed oil ${ }^{14)}$ & Waste cooking oil ${ }^{15)}$ \\
\hline Saponification value (mg KOH/g) & 217.66 & 184.60 & $204.77 \pm 1.40$ \\
Acid value (mg KOH/g) & 200.43 & 5.92 & $2.04 \pm 0.03$ \\
FFA content (\%) & 100.21 & 2.98 & $1.02 \pm 0.02$ \\
Molecular weight (g/mol) & 257.86 & 911.86 & $822.03 \pm 5.63$ \\
Moisture content (wt.\%) & 0.01 & 2.11 & $0.12 \pm 0.00$ \\
\hline
\end{tabular}


the PFAD are palmitic acid and oleic acid.

\subsection{Catalyst characterization}

Thermal profile of the precursor (sample before calcination) is shown in Fig. 1. The first weight loss of about $5 \%$ (range of $100-300{ }^{\circ} \mathrm{C}$ ) was associated to the loss of adsorbed moisture and other volatile traces from the catalyst's surface ${ }^{16)}$. The second weight loss of around

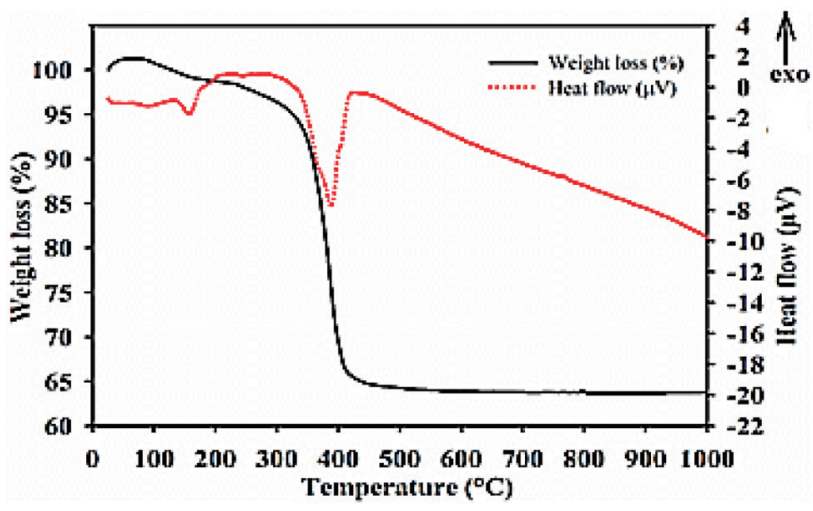

Fig. 1 TGA/DSC curves of precursor obtained
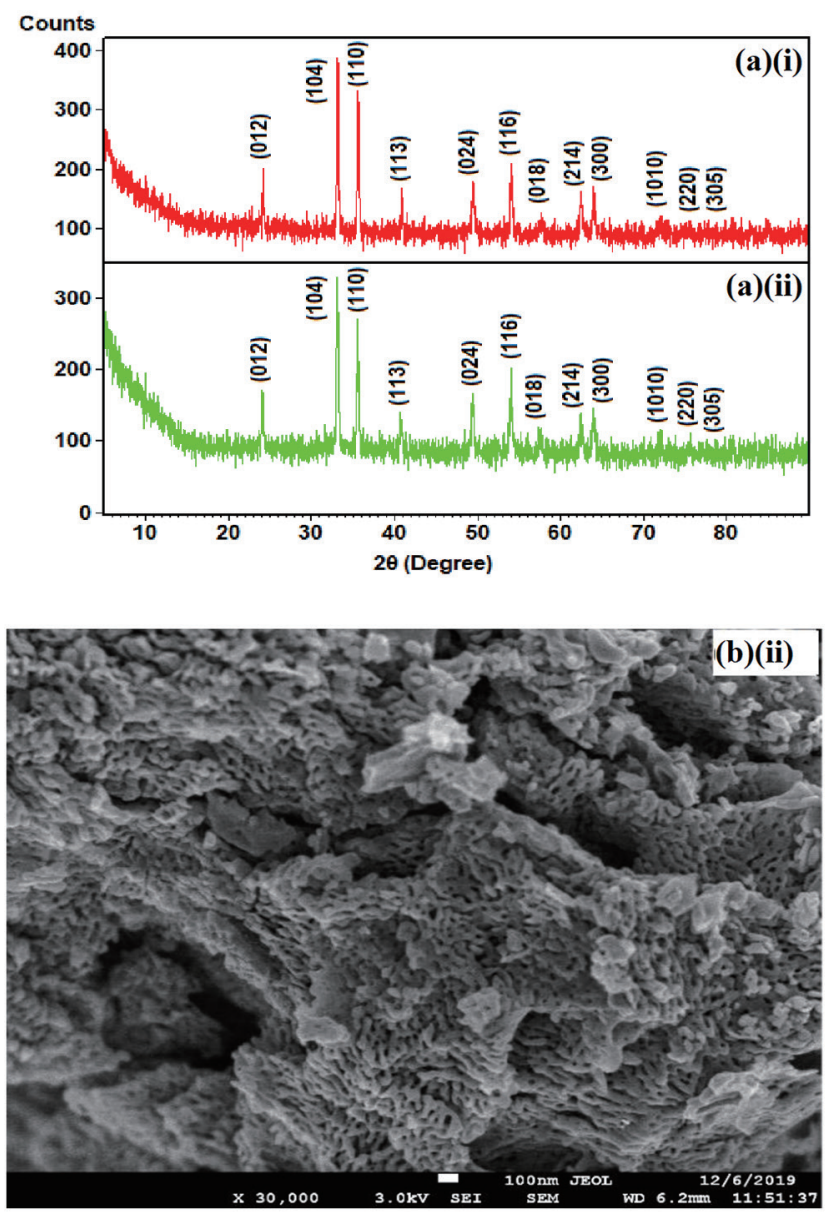

$30 \%$ (between $300^{\circ} \mathrm{C}$ and $500{ }^{\circ} \mathrm{C}$ ) was attributed to the decomposition of the formed precursor into its metal oxide. A plateau of the TGA curve can be seen after $500^{\circ} \mathrm{C}$ onwards with insignificant weight loss, indicating a pure $\mathrm{Fe}_{2} \mathrm{O}_{3}$ is possible to be formed ${ }^{17)}{ }^{18}$. From this plateau, $600^{\circ} \mathrm{C}$ is chosen as the calcination temperature to form a singlephase $\mathrm{Fe}_{2} \mathrm{O}_{3}$ before treated with $\mathrm{HSO}_{3} \mathrm{Cl}$.

Fig. 2 (a) displays the XRD patterns of unsulfonated and sulfonated $\mathrm{Fe}_{2} \mathrm{O}_{3}$ catalysts. Both samples exhibited similar XRD peaks, which belonged to hematite $\left(\alpha-\mathrm{Fe}_{2} \mathrm{O}_{3}\right)$ with a space group of $\mathrm{R}-3 c$ and rhombohedral (hexagonal) crystal structure (ICDD 01-089-0597). The formed catalysts were found to be a single-phase with no impurity peaks detected, suggesting that the SPC method could be used to form pure catalysts. Fig. 2 (b) depicts the surface morphologies of the resultant catalysts. The particles grew and aggregated with changing in shape from polyhedral to the sponge and flaky structures after the deposition of $\mathrm{HSO}_{3}{ }^{-}$ions. The chlorosulfonic acid seemed to affect the surface morphology. A similar observation was also seen in other researchers' study ${ }^{19}$. Subsequently, the Fe, O and S elemental analyses were determined using the EDX
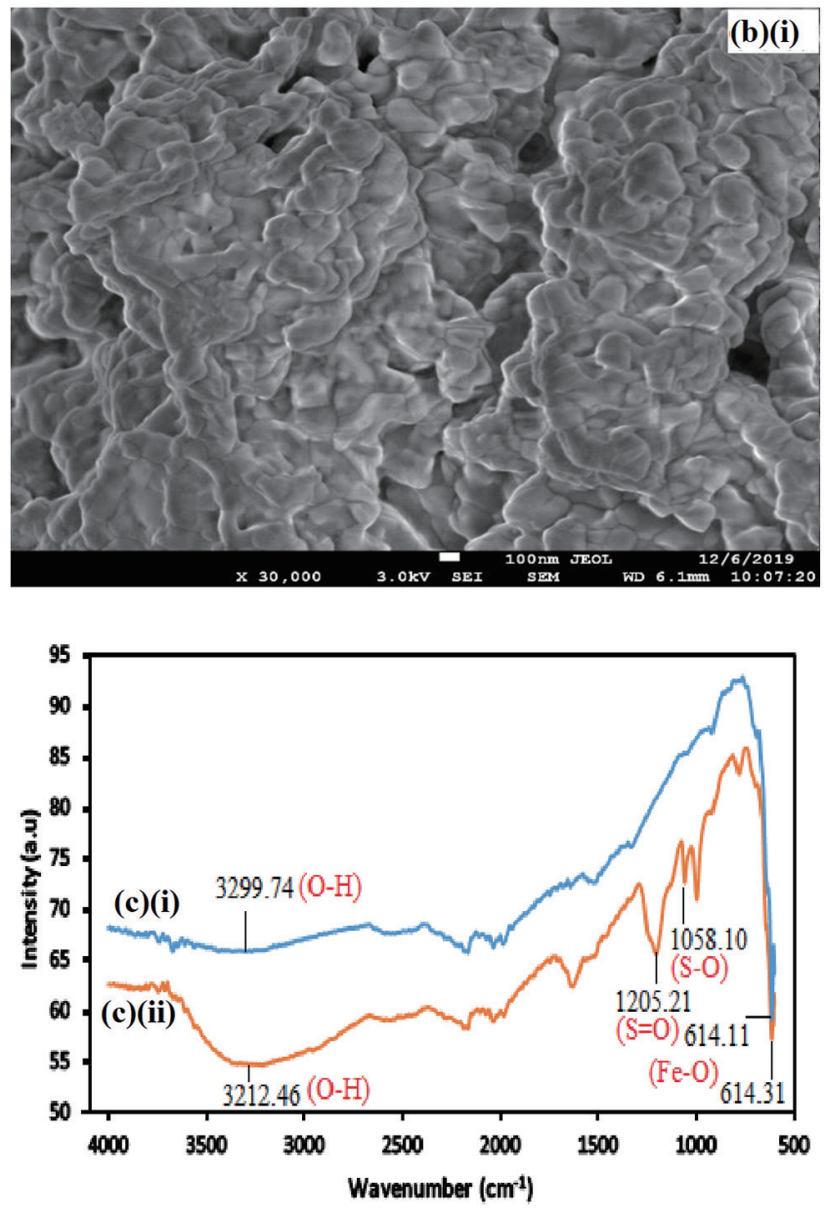

Fig. 2 (a) XRD patterns, (b) FESEM images and (c) FTIR spectra of (i) unsulfonated and (ii) sulfonated $\mathrm{Fe}_{2} \mathrm{O}_{3}$ catalysts 
measurement and tabulated in Table 3. Only the sulfonated $\mathrm{Fe}_{2} \mathrm{O}_{3}$ catalyst showed the existence of element $\mathrm{S}$. The success of sulfonation and incorporation of $\mathrm{HSO}_{3}{ }^{-}$onto the $\mathrm{Fe}_{2} \mathrm{O}_{3}$ surface was further verified using the FTIR spectra in Fig. 2 (c). For the sulfonated $\mathrm{Fe}_{2} \mathrm{O}_{3}$ catalyst, additional absorption bands at $1058 \mathrm{~cm}^{-1}$ and $1205 \mathrm{~cm}^{-1}$ reflect the S-O asymmetric vibration and $\mathrm{S}=\mathrm{O}$ symmetric vibration, which indicated that the covalently linked sulfonic acid group was formed on the catalyst's surface ${ }^{20)}$. Table 4 summarised the textural properties of the catalysts. After the sulfonation, the volume and diameter of the pores increased. This allows the reactants to be in contact with more active sites, and better catalytic activity is expected ${ }^{7)}{ }^{11}$. In addition, the sulfonated $\mathrm{Fe}_{2} \mathrm{O}_{3}$ catalyst displayed three significant peaks at $352{ }^{\circ} \mathrm{C}$ (weak acid sites), $493{ }^{\circ} \mathrm{C}$ (medium acid sites) and $957{ }^{\circ} \mathrm{C}$ (strong acid sites) with total acidity of $1.75 \mathrm{mmol} \mathrm{g}$.

Table 3 Elemental composition analysis of $\mathrm{Fe}_{2} \mathrm{O}_{3}$ catalysts

\begin{tabular}{cccc}
\hline \multirow{2}{*}{ Catalyst } & \multicolumn{3}{c}{ Element (\% weight) } \\
\cline { 2 - 4 } & $\mathrm{Fe}$ & $\mathrm{O}$ & $\mathrm{S}$ \\
\hline Unsulfonated $\mathrm{Fe}_{2} \mathrm{O}_{3}$ & 66.03 & 33.97 & - \\
Sulfonated $\mathrm{Fe}_{2} \mathrm{O}_{3}$ & 64.01 & 35.67 & 0.32 \\
\hline
\end{tabular}

No acid strength and acid site were detected for the nonsulfonated $\mathrm{Fe}_{2} \mathrm{O}_{3}$ catalyst. Therefore, only the sulfonated $\mathrm{Fe}_{2} \mathrm{O}_{3}$ catalyst was used for the PFAD esterification.

\subsection{Catalytic esterification performances}

Theoretically, one mole of FFA reacts with one mole of methanol to produce one mole of FAME ${ }^{21}$. However, the esterification reaction is reversible. Thus, an excess amount of methanol is preferable to shift the reaction forward to the product side ${ }^{21}{ }^{22)}$. The molar ratio of methanol-to-PFAD was changed between 3:1 and 21:1. As shown in Fig. 3 (a), the FFA conversion increased markedly from $27.9 \%$ at $3: 1$ to $87.6 \%$ at $15: 1$. When the amount of methanol increased, the mass transfer limitation among the catalyst-reactantproduct phases also occurred rapidly ${ }^{23)}$. Nevertheless, further increase in the molar ratio resulted in the decrement of FFA conversion. The superfluous methanol may have flooded the catalyst's active sites and hindered the protonation of FFA 22) 24). Besides, excess polar -OH group from the excess methanol may solidify the product and forming gels that are difficult to separate ${ }^{25)}$. Hence, 15:1 was used as the optimal methanol-to-PFAD molar

Table 4 Textural properties of $\mathrm{Fe}_{2} \mathrm{O}_{3}$ catalysts

\begin{tabular}{ccccc}
\hline $\mathrm{Fe}_{2} \mathrm{O}_{3}$ catalyst & $\begin{array}{c}\text { Specific surface area } \\
\left(\mathrm{m}^{2} / \mathrm{g}\right)\end{array}$ & $\begin{array}{c}\text { Total pore volume } \\
\left(\mathrm{cm}^{3} \mathrm{~g}^{-1}\right)\end{array}$ & $\begin{array}{c}\text { Average pore } \\
\text { diameter }(\mathrm{nm})\end{array}$ & $\begin{array}{c}\mathrm{NH}_{3} \text { desorption } \\
\text { temperature }\left({ }^{\circ} \mathrm{C}\right)\end{array}$ \\
\hline Unsulfonated & 7.68 & 0.08 & 41.62 & - \\
Sulfonated & 8.61 & 0.10 & 47.31 & 352 \\
& & & 333.26 & 493 \\
& & & 810.30 & 957 \\
\hline
\end{tabular}
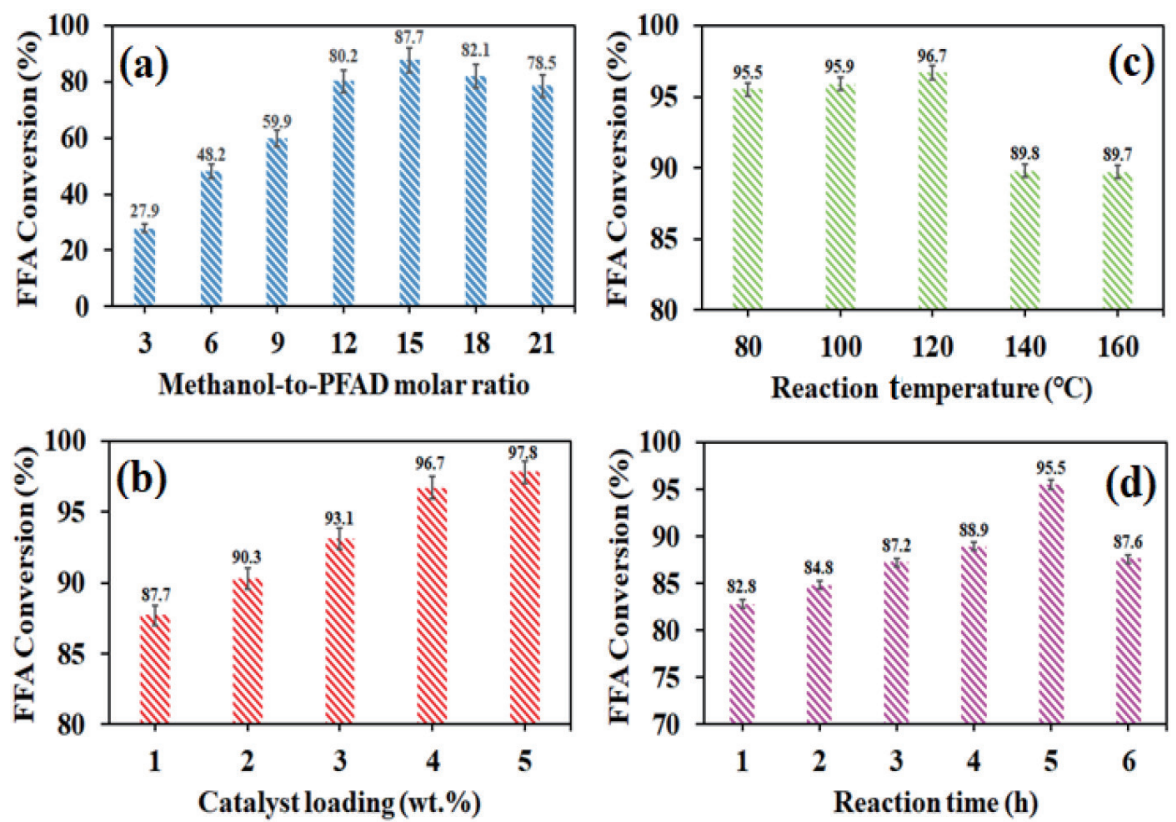

Fig. 3 Effect of (a) methanol-to-PFAD molar ratio ( 1 wt.\%, $120^{\circ} \mathrm{C}$, and $5 \mathrm{~h}$ ), (b) catalyst loading $\left(15: 1,120^{\circ} \mathrm{C}\right.$, and $5 \mathrm{~h}$ ), (c) reaction temperature $(15: 1,4 \mathrm{wt} . \%$, and $5 \mathrm{~h})$ and $(\mathrm{d})$ reaction time $\left(15: 1,4 \mathrm{wt} . \%, 80^{\circ} \mathrm{C}\right)$ on FFA conversion 
ratio. Based on Fig. 3 (b), it can be clearly seen that, when catalyst loading was increased from 1 wt.\% to 5 wt.\%, the FFA conversion raised significantly. The highest conversion of $97.8 \%$ was obtained at catalyst loading of $5 \mathrm{wt} . \%$. This is because the catalyst' $\mathrm{s}$ active site also increases, resulting in more effective collision between reactant and catalyst and faster reaction rate to reach equilibrium ${ }^{5)}{ }^{26)}$. Therefore, 4 wt.\% catalyst loading was chosen as the optimum amount in consideration of insignificant FFA conversion at $5 \mathrm{wt} . \%$ of catalyst loading and cost perspective. For example, production of B10 in Malaysia is priced at RM2.18 per litre. As illustrated in Fig. 3 (c), the FFA conversion increased up to $96.7 \%$ when the reaction temperature was increased from 80 to $120^{\circ} \mathrm{C}$. When temperature increases, reactant molecules gain more kinetic energy which enables them to move faster with more effective collision ${ }^{27}$. As a result, the mass transfer rate accelerated, and higher FAME yield is obtained ${ }^{5)}{ }^{28)}$. However, when the temperature was further increased up to $160^{\circ} \mathrm{C}$, the FFA conversion dropped drastically to $89.7 \%$. This is due to the faster evaporation rate of methanol at a very high temperature, resulting in an insufficient amount of methanol for reaction with oil ${ }^{22)}$. Hence, $80^{\circ} \mathrm{C}$ was chosen as the optimum reaction temperature for lower energy consumption and operating cost. Based on Fig. 3 (d), the FFA conversion increased steadily and maximum FFA conversion of 95.5\% was accomplished at $5 \mathrm{~h}$. Beyond $5 \mathrm{~h}$, the esterification is said to have reached the equilibrium point because most of the reactants has been converted into products and the mass transfer rate among the catalyst-reactant-product phases has reduced ${ }^{23)}$. Thus, production of FAME slows down and the FFA conversion drops to $87.6 \%{ }^{22}$. Besides, the hydrolysis of FAME with the by-product (water) is possible, thus shifting the reaction backwards, lowers the FAME yield and deactivates the catalyst ${ }^{26)}$. Therefore, a reaction time of $5 \mathrm{~h}$ was chosen with a methanol-toPFAD molar ratio of 15:1, catalyst loading of $4 \mathrm{wt} . \%$ and reaction temperature of $80^{\circ} \mathrm{C}$ as the optimum esterification conditions, which effectively catalysed by the sulfonated $\mathrm{Fe}_{2} \mathrm{O}_{3}$ catalyst resulting in the highest FFA conversion of $95.5 \%$.

\section{Conclusion}

In this study, the sulfonated $\mathrm{Fe}_{2} \mathrm{O}_{3}$ catalyst was successfully synthesised and studied for the FFA esterification into biodiesel. The highest FFA conversion of $95.5 \%$ was achieved at the optimized esterification parameters.

\section{Acknowledgement}

The authors would like to acknowledge the Ministry of Higher Education of Malaysia for the financial support under the Fundamental Research Grant Scheme (No. Grant: 600-IRMI/FRGS 5/3 (036/2019)).

\section{References}

1) Atadashi, I. M.; Aroua, M. K.; Abdul, Aziz, A. R.; Sulaiman, N. M. N., Renew Sustain Energy Rev., 16, 32753285 (2016)

2) Bhuiya, M. M. K.; Rasul, M. G.; Khan, M. M. K.; Ashwath, N.; Azad, A. K., Renew Sustain Energy Rev., 55, 1109-1128 (2016)

3) Yusuf, N. N. A. N.; Kamarudin, S. K.; Yaakub, Z., Energy Convers Manag., 52, 2741-2751 (2011)

4) Anwar, M., Fuel, 283, 119204 (2021)

5) Mukti, N. I. F.; Sutrisno, B.; Hidayat, A., IOP Conf Ser Mater Sci Eng., 358 (2018)

6) Kanjaikaew, U.; Tongurai, C.;, Chongkhong, S.; Prasertsit, K., Renew Energy, 119, 336-344 (2018)

7) Wan, Z.; Lim, J. K.; Hameed, B. H., J Taiwan Inst Chem Eng., 54, 64-70 (2015)

8) Szulczyk, K. R.; Khan, M. A. R., J Clean Prod., 203, 260$272(2018)$

9) Mansir, N.; Taufiq-Yap, Y. H.; Rashid, U.; Lokman, I. M., Energy Convers Manag., 141, 171-182 (2017)

10) Zhai, D.; Nie, Y.; Yue, Y.; He, H.; Hua, W.; Gao, Z., Catal Commun., 12, 593-596 (2011)

11) Widayat, W.; Putra, D. A.; Nursafitri, I., Mater Today Proc., 13, 97-102 (2019)

12) Ezzah-Mahmudah, S.; Lokman, I. M.; Saiman, M. I.; Taufiq-Yap, Y. H., Energy Convers Manag., 126, 124-131 (2016)

13) Fadhil, A. B.; Aziz, A. M.; Al-Tamer, M. H., Energy Convers Manag., 108, 255-265 (2016)

14) Omotehinse, S. A; Igboanugo, A. C.; Ikhuoria, E. U.; Ehigie, C. A., Journal of Science and Technology Research, 1, 45-54 (2019)

15) Chuah L. F.; Suzana Y.; Aziz, A.; Bokhari A., Australian Journal of Basic and Applied Sciences., 9, 10 445-448 (2015)

16) Basavegowda, N.; Mishra, K.; Lee, Y. R., Adv Nat Sci Nanosci Nanotechnol., 8, (2017)

17) Soltani, S.; Rashid, U.; Nehdi, I. A.; Al-Resayes, S. I., Chem Eng Technol., 40, 1931-1939 (2017)

18) Yahya, N. F.; Kamarulzaman, N.; Elong, K. et al., AIP Conf Proc., 1877, (2017)

19) Kaur, K.; Wanchoo, R. K.; Toor, A. P., Ind Eng Chem Res., 54, 3285-3292 (2015)

20) Istadi, I.; Anggoro, D. D.; Buchori, L.; Rahmawati, D. A.; 
Intaningrum, D., Procedia Environ Sci., 23, 21 385-393 (2015)

21) Gupta, A. R.; Chiplunkar, P. P.; Pratap, A. P.; Rathod, V. K., Waste and Biomass Valorization, 12(1), 25 (2020)

22) Syazwani, O. N.; Rashid, U.; Mastuli, M. S.; Taufiq-Yap Y. H., Renew Energy, 131, 187-196 (2019)

23) Omar, W. N. N. W.; Amin, N. A. S., Biomass and Bioenergy, 35, 1329-1338 (2011)

24) Juan, J. C.; Zhang, J.; Jiang, Y.; Cao, W.; Yarmo, M. A., Catal Letters, 117, 153-158 (2007)
25) Mohd. Ali, M. A.; Yunus, R. M.; Cheng, C. K.; Gimbun, J., RSC Adv., 5, 76743-76751 (2015)

26) Olutoye, M. A.; Wong, C. P.; Chin, L. H.; Hameed, B. H., Fuel Process Technol., 124, 54-60 (2014)

27) Ibrahim, N. A.; Rashid, U.; Choong, T. S. Y.; Nehdi, I. A., RSC Adv., 10, 6098-6108 (2020)

28) Mastuli, M. S.; Kamarulzaman, N.; Kasim, M. F.; Zainal, Z.; Matsumura, Y.; Taufiq-Yap Y. H., Int J Hydrogen Energy, 44, 3690-3701 (2019) 